\title{
STRONG CONVERGENCE THEOREMS OF MODIFIED MANN ITERATIVE PROCESS FOR NONEXPANSIVE MAPPINGS IN HILBERT SPACES
}

\author{
HAIFANG LIU AND RUDONG CHEN
}

Abstract. The purpose of this article is to modify normal Mann's iterative process to have strong convergence for nonexpansive mappings in the formework of Hilbert spaces. We prove the strong convergence of the proposed iterative algorithm to the fixed point of nonexpansive mappings which is the unique solution of a variational inequality, which is also the optimality condition for a minimization problem.

Mathematics subject classification (2010): 47H09, 47H10, 47H05, 58E35.

Keywords and phrases: Nonexpansive mapping, strong positive operator, variational inequality, iterative algorithm.

\section{REFERENCES}

[1] Yonghong Yao, Muhammad Aslam Noor, Rudong Chen, Yeong-Cheng Liou, Strong convergence of three-step relaxed hybrid steepest-descent methods for variational inequalities, Applied Mathematics and Computation, 201, 1-2 (2008), 175-183.

[2] YANRONG YU AND RUdONG CHEN, Hybrid steepest-descent method for general variational inequalities, Journal of Inequalities and Applications, 2007 (2007), Article ID 19270, 14 pp.

[3] HideAKI IIDUKA, Is AO YAMADA, A use of conjugate direction for the convex optimization problem over the fixed point set of a nonexpansive mapping, SLAM J. OPTIM., 19, 4 (2009), 1881-1893.

[4] I. YAMADA, The hybrid steepest descent method for the variational inequality problem over the intersection of fixed point sets of nonexpansive mappings, in Inherently Parallel Algorithms for Feasibility and Optimization and Their Applications (D. Butnariu, Y. Censor and S. Reich, Eds.), Elsevier, 2001, pp. 473-504.

[5] I. YAMADA AND N. OGURA, Hybrid steepest descent method for variational inequality problem over the fixed point set of certain quasi-nonexpansive mapping, Numer. Funct. Anal. Optim., 25 (2004), 619-655.

[6] I. Yamada, N. OgURA, AND N. ShIRAKAWA, A numerical robust hybrid steepest descent method for the convexly constrained generalized inverse problems, Contemp. Math., 313 (2002), 269-305.

[7] S. REICH, Weak convergence theorems for nonexpansive mappings in Banach spaces, J. Math. Anal. Appl., 67 (1979), 274-276.

[8] T. H. Kim, H. K. XU, Strong convergece of modified Mann iterations, Nonlinear Anal., 61 (2005), $51-60$.

[9] H. IIDUKA, W. TAKAHASHI, Strong convergence theorems for nonexpansive mappings and inversestrongly monotone mappings, Nonlinear Anal., 61 (2005), 341-350.

[10] G. MARINO, H. K. XU, Weak and strong convergence theorems for $k$-strict pseudo-contractions in Hilbert spaces, J. Math. Anal. Appl., 329 (2007), 336-349.

[11] X. QIn, Y. SU, Approximation of a zero point of accretive operator in Banach spaces, J. Math. Anal. Appl., 329 (2007), 415-424.

[12] G. Marino, H. K. XU, A general iterative method for nonexpansive mappings in Hilbert spaces, J. Math. Anal. Appl., 318 (2006), 43-52.

[13] Yisheng SONG, RUDONG CHEN, Strong convergence theorems on an iterative method for a family of finite nonexpansive mappings, Applied Mathematics and Computation, 180, 1 (2006), 275-287. 
[14] Yisheng Song, Rudong Chen, Weak and strong convergence of Mann's-type iterations for a countable family of nonexpansive mappings, Journal of the Korean Mathematical Society, 45, 5 (2008), 1393-1404.

[15] Rudong Chen, Yunyan Song, Strong Convergence to Common Fixed Point of Nonexpansive Semigroups In Banach Space, Journal of Computational and Applied Mathematics, 200, 2 (2007), $566-575$.

[16] Y. YAO, R. ChEN, J. C. YAO, Strong convergence and certain control conditions for modified Mann iteration, Nonlinear Anal., 68, 6 (2008), 1687-1693.

[17] K. NAKAJO, W. TAKAHASHI, Strong convergence theorems for nonexpansive mappings and nonexpansive semigroups, J. Math. Anal. Appl., 279 (2003), 372-379.

[18] Hong-Kun XU, Viscosity approximation methods for nonexpansive mappings, J. Math. Anal. Appl., 298 (2004), 279-291.

[19] T. SUZUKI, Strong convergence of Krasnoselskii and Mann's type sequence for one-parameter nonexpansive semigroups without Bochner intergral, J. Math. Anal. Appl., 305, 1 (2005), 227-239.

[20] F. E. BRowder, W. V. Petryshyn, Construction of fixed points of nonlinear mappings in Hilbert space, J. Math. Anal. Appl., 20 (1967), 197-228.

[21] H. ZHOU, Convergence theorems of fixed points for $k$-strict pseudo-contractions in Hilbet space, Nonlinear Anal., 69, 2 (2008), 456-462.

[22] H. K. XU, An iterative approach to quadratic optimization, J. Optim. Theory Appl., 116 (2003), 659-678.

[23] Yonghong Yao, Rudong Chen, Haiyun Zhou, Strong convergence to common fixed points of nonexpansive mappings without commutativity assumption, Fixed Point Theory and Applications, Art. No. 89470, 2006. 